\title{
Satisfaction with Nursing Care among Patients Attending Oncology Center in Basra City, Iraq
}

\author{
Samira Muhammed Ebrahim ${ }^{1}$ and Sajjad Salim Issa ${ }^{2}$ \\ 1 Department of Basic Medical Science, University of Basra, Basra 61001, Iraq \\ 2 Department of Nursing Science, University of Basra, Basra 61001, Iraq
}

\begin{abstract}
This study was carried out on a sample of 100 patients attending outpatient oncology center in Basra governorate located in south of Iraq. In order to assess their satisfaction with nursing care quality and identify the relationship between their satisfaction rate and selected variables. The results showed that high satisfaction rate for the technical quality 87 (87\%) followed by interpersonal communication dimension $86(86 \%)$ while the lowest satisfaction rate was for the information given by the nurse 64 (64\%). There were no statistical differences among the age of the patients, their education, their marital status and occupation. Furthermore, the satisfaction level with nursing care except for females who reported significantly higher level of satisfaction with nursing technical quality.
\end{abstract}

Key words: Satisfaction, patients, nursing care, technical quality, communication, information.

\section{Introduction}

Patient satisfaction is significant and usually used as an indicator for measuring the degree of excellence in health care. Patient satisfaction is the patient's perception of care received compared with the care expected [1]. Nurses act reciprocally with patients more frequently than any other health care staff in a hospital. Nurse acts in translating information given by doctors in a highly skilled manner with a human touch [2].

Patients have their internal expectation for nurses' caring, manner and attitudes and nurses' performance of caring behavior, this expectation has a direct impact on the patients' feelings. Therefore, it is great important for all nurses to keep improving their oncology professional knowledge, attitudes, skills as well as their capability of offering support in the fields of information, emotion and technical support and help for their cancer patients [3].

Contemporary healthcare systems try to adopt a

Corresponding author: Samira Muhammed Ebrahim, Ph.D., main research field: community medicine. E-mail: samira_m_ebrahim@yahoo.com. more customer-oriented access to the delivery of healthcare. With this shift, patient satisfaction and quality of life are becoming more and more significant as the more traditional clinic effects in the monitoring and evaluation of healthcare delivery. So, the assessment of patient satisfaction submits a way of improving health status and prevents misuse of medical resources [4].

There are only a few reports of patient satisfaction from developing countries, with comparing to the high volume of publications on patient satisfaction from developed countries [1]. In India, 609 patients across 6 Tertiary Cancer Treatment Hospitals that were selected from 6 regions were interviewed. The study reveals that above $70 \%$ of the patients were satisfied with the facilities, doctors, nurses, services and care, except on the few items like information supported by doctor or nurses and the facilities for attendants [5].

In Irana, study was conducted on 384 cancer patients in the oncology wards of 10 teaching-hospitals of two main government universities, revealing that a vast majority of these respondents $(82.8 \%)$ were satisfied with the nursing care provided to them, while the others $(17.2 \%)$ were not [1]. 
Studying patient satisfaction with chemotherapy care at Worthing Hospital, UK. Patient satisfaction levels were generally high in the 173 patients who provided data, with $97 \%$ of patients happy with the service overall. Overall, satisfaction was strongly associated with patient compliance. Satisfaction was expressed most consistently with chemotherapy nursing care, while lower satisfaction levels were associated with patient information in particular [6].

Local studies conducted in Iraq about patient satisfaction with nursing care but not for cancer patients, one of these studies was conducted in Thiqar on 452 clients from 5 different public health care facilities at Alnassirya city, showing that 222 (49.1\%) were dissatisfied with the health care services offered by facilities. High dissatisfaction rate was associated with low education, unemployment, male gender and being single [4].

In Baghdad, a study conducted on 150 patients at hemodialysis units, teaching hospitals was selected, showing that there is high satisfaction to clinical nursing care, communication/patient-nurse relationship and moderate satisfaction toward nursing health education [7].

Objectives of the study:

(1) To assess the patient satisfaction with nursing care quality;

(2) To identify the relationship of satisfaction with selected variables.

\section{Methodology}

Descriptive, Cross Sectional Study conducted in Oncology center in Basra governorate south of Iraq. A convenient sample of 100 patients attending outpatient oncology center were selected. Structured questionnaire was used for the purpose of data collection, which was carried out from December 2014 through February 2015.

The questionnaire was adopted and modified from a study done elsewhere $[1,8,9]$. The questionnaire contains items related to socio-demographic characteristics of the patients and items to the disease and satisfaction with three aspects of nursing care as technical quality, interpersonal communication and information given by the nurse. Standardized 5-point Likert scales ranging from strongly unsatisfied to strongly satisfied ( 1 to 5 points) were used for all the 20 items. Patient satisfactions were classified into two categories - satisfied and not satisfied by using the demarcation threshold from Eq. (1):

$$
\left(\frac{\text { total highest score }- \text { total lowest score }}{2}\right)+
$$

Total lowest score

The data was collected via face-to-face interviews by two fourth year nursing college students, and the translated Patient Satisfaction Questionnaire in Arabic was used to guide the interview. These patients were interviewed when they were in good situation (before their chemotherapy and immunotherapy etc.). Each interview session took about 10-15 minutes.

Before any attempt to collect data, approval to conduct the study was obtained from general health directorate of Basra.

Also, each participant (patient) was informed the aim of the study, they have the right to refuse to participate in the study, and confidentiality of the information gathered. Furthermore, patients with first visit were excluded.

Data analysis was made by using SPSS version 17 and data was expressed in frequency and percentage. Chi-squared test was used to examine the association between the groups and a probability of less than 0.05 was considered to be statistically significant.

\section{Results}

Table 1 showed that 73 (73\%) of the studied sample were males, the majority of the sample were below 60 years of age, high percent of them $(77(77 \%))$ were married. Concerning occupational status of the sample $35(35 \%)$ were self employed, 12 (12\%) were students, 33 (33\%) were employed, 13 (13\%) were house wives and $7(7 \%)$ were retired, regarding formal education $28(28 \%)$ had primary school followed by 27 (27\%) 
had secondary school and only $4(4 \%)$ of them had higher education. Regarding the area of residence the majority (92 (92\%)) of the sample were from Basra governorates.

Regarding the onset of treatment $51(51 \%)$ of the patients start chemotherapy treatment before 6 months, the majority $(55(55 \%))$ of them receive treatment once monthly and for the most of patients, each setting last for less than 6 hours as shown in Table 2.

Table 3 showed that the high average satisfaction rate was for the technical quality $(87(87 \%))$ followed by interpersonal communication dimension (86 $(86 \%)$ ), while the lowest satisfaction rate was for the information given by the nurse (64 (64\%)).

In Table 4, higher satisfaction rate was reported among females $(100(100 \%))$ than among males 60 $((82.2 \%))$ for technical quality of care and the difference was statistically significant. Also among females, a higher level of satisfaction $(26(96.3 \%))$ was reported than among males $(60(82.2 \%))$ for

Table 1 Socio demographic characteristics of respondents $(n=100)$.

\begin{tabular}{|c|c|c|c|}
\hline Characteristics of respondents & Categories/groupings & Frequency & Percent $(\%)$ \\
\hline \multirow{2}{*}{ Gender } & Male & 73 & 73 \\
\hline & Female & 27 & 27 \\
\hline \multirow{5}{*}{ Age in years } & $<20$ & 10 & 10 \\
\hline & $20-29$ & 22 & 22 \\
\hline & $30-39$ & 18 & 18 \\
\hline & $40-59$ & 38 & 38 \\
\hline & 60 and more & 12 & 12 \\
\hline \multirow{2}{*}{ Marital status } & Single & 23 & 23 \\
\hline & Married & 77 & 77 \\
\hline \multirow{5}{*}{ Occupation } & Students & 12 & 12 \\
\hline & Employed & 33 & 33 \\
\hline & Self employed & 35 & 35 \\
\hline & Retired & 7 & 7 \\
\hline & Housewife & 13 & 13 \\
\hline \multirow{6}{*}{ Level of education } & Illiterate & 6 & 6 \\
\hline & Read and write & 11 & 11 \\
\hline & Primary & 28 & 28 \\
\hline & Secondary & 27 & 27 \\
\hline & College & 24 & 24 \\
\hline & Higher education & 4 & 4 \\
\hline \multirow{2}{*}{ Area of residence } & Basra & 92 & 92 \\
\hline & Other governorate & 8 & 8 \\
\hline
\end{tabular}

Table 2 Information regarding therapy $(n=100)$.

\begin{tabular}{llll}
\hline Variable & Categories & Number & Percents (\%) \\
\hline \multirow{4}{*}{ Onset of starting chemotherapy } & Before one month & 23 & 23 \\
& Before three months & 25 & 25 \\
& Before six months & $\underline{51}$ & 51 \\
& Before one year & 1 & 1 \\
& Once per week & 4 & 4 \\
Frequency of therapeutic settings & Twice per week & 29 & 29 \\
& Once per month & $\underline{55}$ & 12 \\
& Twice per month & 12 & 45 \\
Duration of each therapeutic setting & $1-2$ hours & 45 & 48 \\
& $3-5$ hours & 48 & 7 \\
\hline
\end{tabular}


Table 3 Frequency distribution level of average satisfaction within three dimensions of Nursing Care $(\mathbf{n}=100)$.

\begin{tabular}{lllll}
\hline \multirow{2}{*}{ Dimensions of nursing care } & \multicolumn{3}{c}{ Satisfied } & \multicolumn{2}{c}{ Not satisfied } \\
\cline { 2 - 5 } & No. & $\%$ & No. & 13 \\
\hline Technical quality & 87 & 87 & 14 & 14 \\
Interpersonal communication & 86 & 86 & 36 & 36 \\
Information given by the nurse & 64 & 64 & 36 \\
\hline
\end{tabular}

Table 4 Frequency of satisfied/not satisfied patients within three dimensions of nursing care in relation to gender $(n=100)$.

\begin{tabular}{|c|c|c|c|c|c|c|c|c|}
\hline \multirow{2}{*}{ Technical quality } & \multirow{2}{*}{ Gender } & \multicolumn{2}{|c|}{ Satisfied } & \multicolumn{2}{|c|}{ Not satisfied } & \multirow{2}{*}{$X^{2}$} & \multirow{2}{*}{ df } & \multirow{2}{*}{$\mathrm{p}$-value } \\
\hline & & No. & $\%$ & No. & $\%$ & & & \\
\hline \multirow{6}{*}{ Interpersonal communication } & Male & 60 & 82.2 & 13 & 17.8 & \multirow{3}{*}{5.257} & \multirow{3}{*}{1} & \multirow{3}{*}{0.019} \\
\hline & Female & 27 & $\underline{100}$ & 0 & 0 & & & \\
\hline & Total & 87 & 87 & 13 & 13 & & & \\
\hline & Male & 60 & 82.2 & 13 & 17.8 & & & \\
\hline & Female & 26 & $\underline{96.3}$ & 1 & 3.7 & 3.257 & 1 & 0.071 \\
\hline & Total & 86 & 86 & 14 & 14 & & & \\
\hline \multirow{3}{*}{ Information given by the nurse } & Male & 48 & 65.8 & 25 & 34.2 & \multirow{3}{*}{0.361} & \multirow{3}{*}{1} & \multirow{3}{*}{0.548} \\
\hline & Female & 16 & $\underline{59.3}$ & 11 & 40.7 & & & \\
\hline & Total & 64 & 64 & 36 & 36 & & & \\
\hline
\end{tabular}

interpersonal communication dimension and the difference was statistically not significant. While satisfaction regarding the information given by the nurse, males showed higher level 48 (65.8\%) than females $16(59.3 \%)$ and the difference was statistically not significant.

In Table 5, regarding satisfaction with technical quality dimension the higher rate (90.0\%) was reported among younger age groups below 30 years of age. While for satisfaction with both interpersonal communication and information given by the nurse, the higher rate was reported among those 60 years old and over $91.7 \%$.

Table 5 also showed that there was no statistical significant difference between the age of the patients and satisfaction level for the three dimensions.

Table 6 showed that for all educational levels the satisfaction rate was lower for the dimension of information given by the nurse than the other dimensions.

Table 6 also showed that there had not been a statistical significant difference between patients' educational status and their satisfaction sections (technical quality, interpersonal communication and the information given by the nurse).
Table 7 showed that higher satisfaction rate among singles patients for both technical quality (21 (91.3\%)) and for interpersonal communication $(20(87 \%))$ than married patient. While for information given by the nurse single patients reported lower satisfaction rate (14 $(60.9 \%))$. However, the differences were statistically not significant.

Table 8 showed that highest satisfaction rate among house wives and students for technical quality (100\%). House wives showed $13(100 \%)$ satisfaction for interpersonal communication followed by students 11 $(91.7 \%)$, while the lowest satisfaction rate reported by housewives was for information given by the nurse ( 7 $(53.8 \%))$. The differences between patients' occupational status and their satisfaction for the three dimensions were statistically not significant.

\section{Discussion}

Satisfaction studies can operate to offer care providers some ideas of the ways they would have to adjust their measures of caring in order to make their patients more satisfied. Nursing management is a very important factor in patients' satisfaction or dissatisfaction with their experiences in hospital, and nurses' attitudes towards and communication with 
Table 5 Frequency of satisfied/not satisfied patients within three dimensions of nursing care in relation to age $(n=100)$.

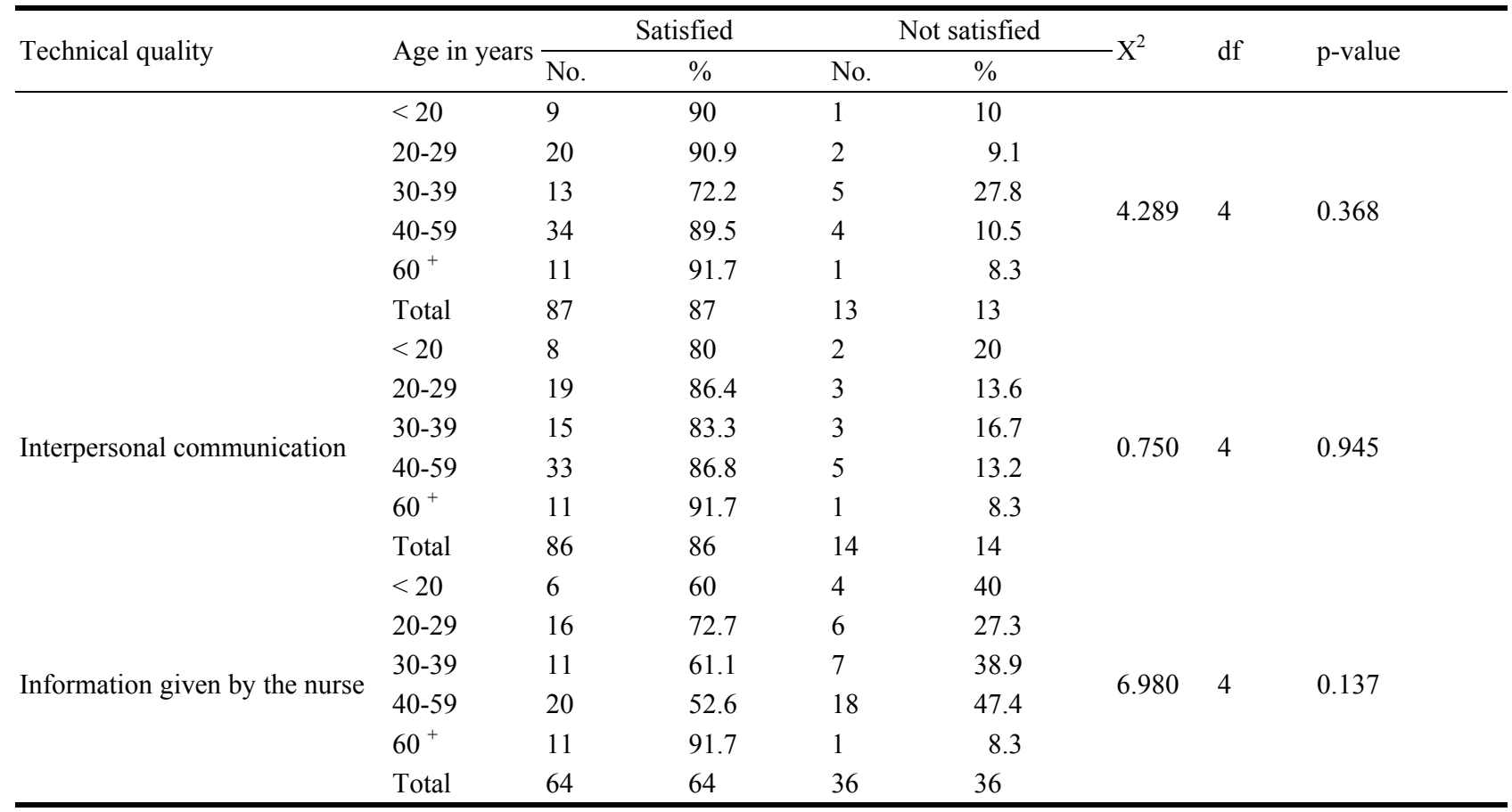

Table 6 Frequency of satisfied/not satisfied patients within three dimensions of nursing care in relation to patient education $(n=100)$.

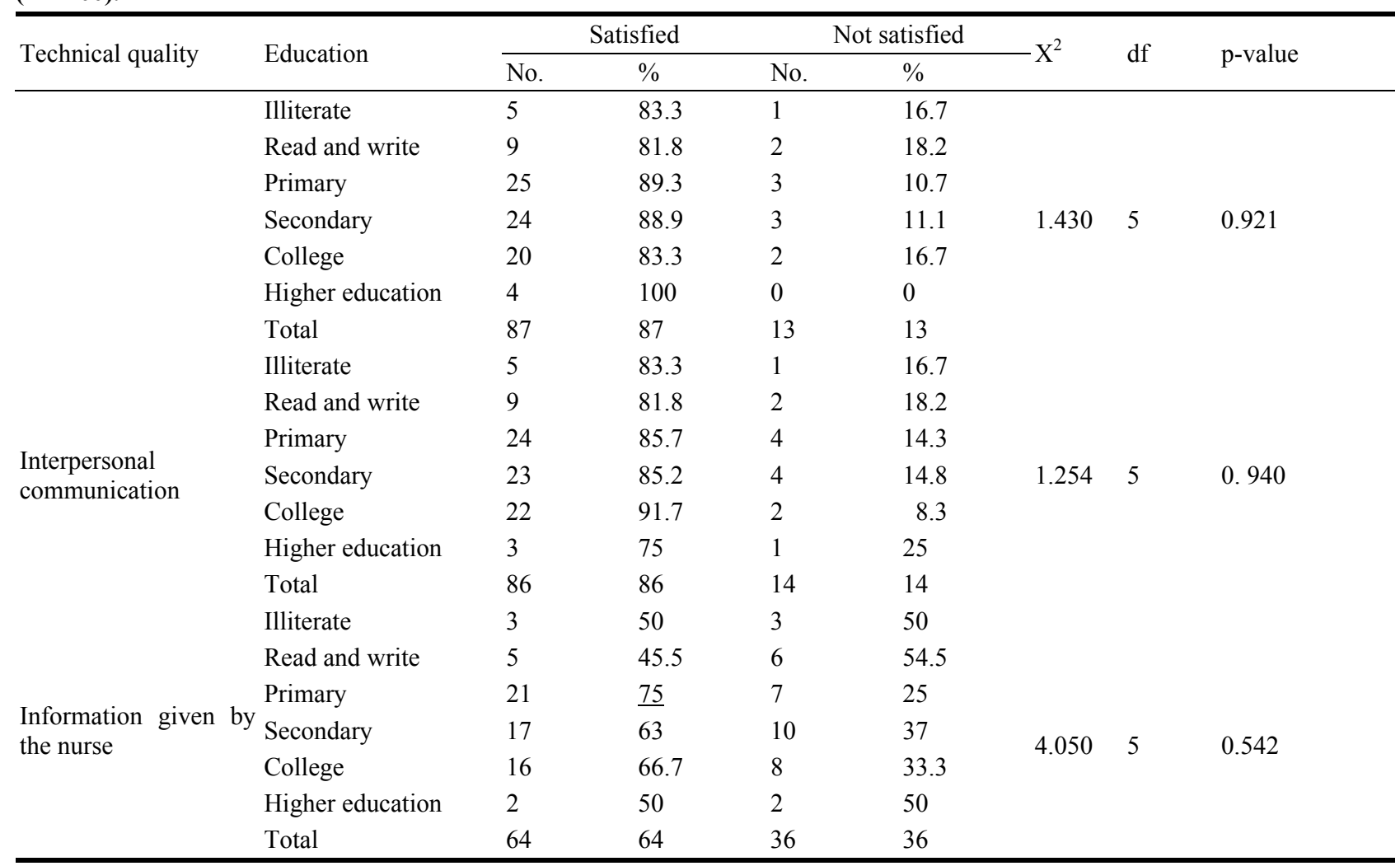


Table 7 Frequency of satisfied/not satisfied Patients within three dimensions of nursing care in relation to marital state $(\mathrm{n}=100)$.

\begin{tabular}{|c|c|c|c|c|c|c|c|c|}
\hline \multirow{2}{*}{ Technical quality } & \multirow{2}{*}{ Marital state } & \multicolumn{2}{|c|}{ Satisfied } & \multicolumn{2}{|c|}{ Not satisfied } & \multirow{2}{*}{$-X^{2}$} & \multirow{2}{*}{$\mathrm{df}$} & \multirow{2}{*}{ p-value } \\
\hline & & No. & $\%$ & No. & $\%$ & & & \\
\hline \multirow{6}{*}{$\begin{array}{l}\text { Interpersonal } \\
\text { communication }\end{array}$} & Single & 21 & $\underline{91.3}$ & 2 & 8.7 & \multirow{3}{*}{0.489} & \multirow{3}{*}{1} & \multirow{3}{*}{0.084} \\
\hline & Married & 66 & 85.7 & 11 & 14.3 & & & \\
\hline & Total & 87 & 87 & 13 & 13 & & & \\
\hline & Single & 20 & $\underline{87}$ & 3 & 13 & & & \\
\hline & Married & 66 & $\overline{85.7}$ & 11 & 14.3 & 0.023 & 1 & 0.880 \\
\hline & Total & 86 & 86 & 14 & 14 & & & \\
\hline \multirow{3}{*}{$\begin{array}{l}\text { Information given by } \\
\text { the nurse }\end{array}$} & Single & 14 & 60.9 & 9 & 39.1 & \multirow{3}{*}{0.127} & \multirow{3}{*}{1} & \multirow{3}{*}{0.722} \\
\hline & Married & 50 & 64.9 & 27 & 35.1 & & & \\
\hline & Total & 64 & 64 & 36 & 36 & & & \\
\hline
\end{tabular}

Table 8 Frequency of satisfied/not satisfied Patients within three dimensions of nursing care in relation to occupation $(n=100)$.

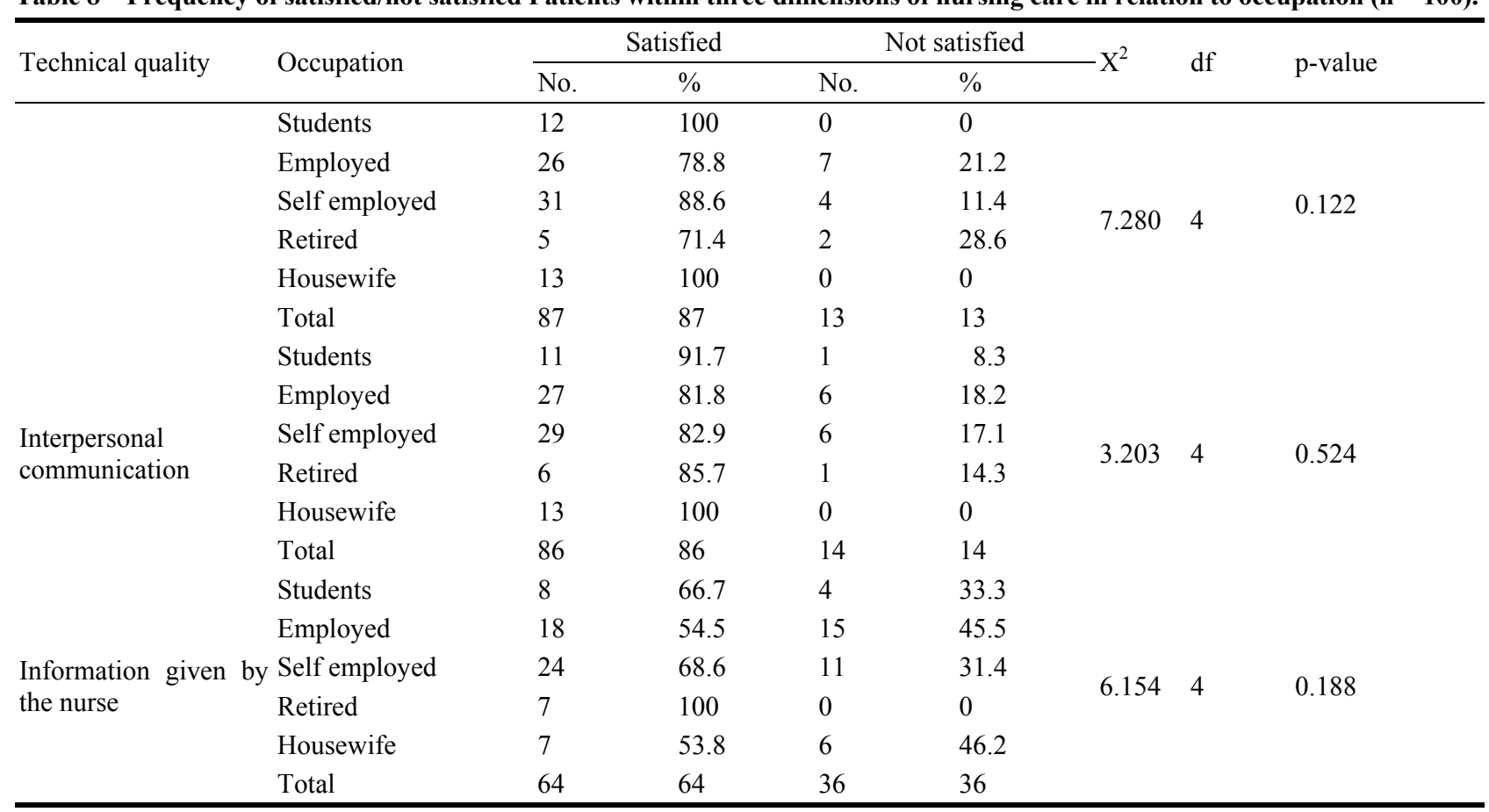

patients are the essential determinants of the patient satisfaction [7]. Even though, there may be competent physicians present in a given health institution, it would be inadequate without appropriate nursing care [9]. Patient' satisfaction with nursing is considered the most significant factor in the molding of the overall patient satisfaction with hospital care [10].

By observing, the reported data about the onset of cancer, frequency of therapeutic settings and the duration of each setting, patients in this study were able to observe and explore the work of nurses and express their state of satisfaction.

In this study, high satisfaction rate was reported for both technical quality $(87 \%)$, interpersonal communication dimension (86\%) and lowest for the information given by the nurse (64\%) compared to study conducted in Tehran. Iran were most of the respondents were satisfied with the amount of information given by the nurses (294 (76.6\%)), interpersonal relationship (371 $(96.6 \%))$, technical quality $(295(76.8 \%))$ [1]. Other study of patient satisfaction with quality of services providers at the tertiary care cancer hospitals in India revealed that nearly $72 \%-80 \%$ of the patients were satisfies with various aspects related with Nursing Care [5].

The type and amount of information given to a 
patient about their condition and treatment are of great importance in health care. The result of this study regarding satisfaction with information given by the nurses was $64 \%$, much higher compared to $14 \%$, which was reported in study done to investigate the in-patient satisfaction with nursing care among 100 patients in Ghana [9]. But, lower than 78.1\%, which was reported form 611 cancer patients interviewed from 6 Tertiary Cancer Treatment Hospitals/Regional Cancer Centers from the six region of India [5]. Also, lower than the result of a cross sectional study which was conducted Tehran, Iran. It showed out of 384 cancer patients, 294 (76.6\%) were satisfied with the amount of information given by the nurses [1].

Higher satisfaction rate was reported among females for technical quality of care and the difference was statistically significant. Females showed higher level of satisfaction for interpersonal communication and the difference was statistically not significant. This could be explained that females had fewer expectations than males. While satisfaction regarding the information given by the nurse, males showed higher level than females although the difference was statistically not significant. Similar finding was reported in other study which was conducted in Iran, suggesting that male patients spontaneously receive more information from nursing staff than female patients [11].

The level of satisfaction was higher among elderly patient. A probably explanation that older people possibly putting much value on the nursing care they get when their own need of care is at its maximum. Also it could be that older patients expecting less information from their nurses on their care as compared to the younger patients who had a lot of problems inclosing their care $[1,9]$.

No statistical significant difference between patient educational status and their satisfaction rate (technical quality, interpersonal communication and the information given by the nurse), this is consistent with other study in Baghdad [7]. The study revealed no statistical differences between marital status and satisfaction dimensions. Similar with findings reported by previous studies conducted in Bagdad and Malaysia [7, 12].

\section{Conclusions}

This study found out that most of the respondents were satisfied with the nursing technical quality and interpersonal communication. The least satisfaction was for the information given by the nurse.

\section{Recommendations}

It is important to continue improving the oncology professional knowledge, attitudes and skills of the nurses dealing with cancer patients as well as improving their skills of providing knowledge and emotional support for their patients through participation in health education programs.

\section{References}

[1] Akhtari-Zavare, M., Abdullah, M. Y., Syed, S. Hassan, Binti, S. Said, and Kamali, M. 2010. "Patient Satisfaction: Evaluating Nursing Care for Patients Hospitalized with Cancer in Tehran Teaching Hospitals, Iran." Global Journal of Health Science 2 (1): 117-126.

[2] Ghiwet, L., and Kidanu, K. 2014. "Assessment of Patient's Perception and Expectation to Wards Nursing Care in Ayder Referal Hospital. Mekelle City, Northern Ethiobia, Across Sectional Study." International Journal of Nursing Education and Research 1 (1): 4-11.

[3] Liu, J. E., Mok, E., and Wong, T. 2005. "Caring in Nursing: Investigating the Meaning of Caring from the Perspective of Cancer Patients in Beijing, China." Journal of Clinical Nursing 15: 188-196.

[4] Sa'adoon, A. A., Hussein, A. H., and Museher, T. R. 2008. "Patients' Satisfaction for Health Care Services at Thi-qar Province, Iraq.” Thi-Qar Medical Journal 2 (1): 39-45.

[5] Piang, L. K., Tiwari, V. K., Nair, K. S., Raj, S., Kaur, H., and Gandotra, R. 2012. "Patients Satisfaction with Quality of Services Providers at the Tertiary Care Cancer Hospitals in India." Indian J. Prev. Soc. Med. 43 (4): 396-404.

[6] Sitzia, J., and Wood, N. 1998. "Study of Patient Satisfaction with Chemotherapy Nursing Care." European Journal of Oncology Nursing 2 (3): 142-153. 
[7] Shnishil, A. T., and Mansour, K. A. 2013. "Assessment of Patients' Satisfaction Toward Nursing Care at Hemodialysis Units." Iraqi National Journal of Nursing Specialties 26 (1): 1-9.

[8] Molla, M., Berhi, M., Shumye, A., and Adama, Y. 2014. "Assessment of Adult Patients Satisfaction and Associated Factors with Nursing Care in Black Lion Hospital Ethiopia; Institutional Bases Cross Sectional Study, 2012." International Journal of Nursing and Midwifery 6 (4): 49-57.

[9] Dzomeku, V. M., Ba-Etilayoo, A., Perekuu, T., and Mantey, R. E. 2013. "In-Patient Satisfaction with Nursing Care: A Case Study at Kwame Nkrumah University of Science and Technology Hospital.” International Journal of Research In Medical and Health Sciences 2 (1): 19-24.

[10] Merkouris, A., Andreadou, A., Athini, E., Hatzimbalasi, M., Rovithis, M., and Papastavrou, E. 2013. “Assessment of Patient Satisfaction in Public Hospitals in Cyprus: A Descriptive Study." Health Science Journal 7 (1): 28-40.

[11] Rafii, F., Hajinezhad, M. E., and Haghani, H. 2009. "Nurse Caring in Iran and Its Relationship with Patient Satisfaction." Australian Journal of Advanced Nursing 26 (2): 75-84.

[12] Tang, W. M., Soong, C. Y., and Lim, W. C. 2013. "Patient Satisfaction with Nursing Care: A Descriptive Study Using Interaction Model of Client Health Behavior." International Journal of Nursing Science 3 (2): 51-56. 